Ueber die Bemerkungen von V. Hensen zu meinem Aufsatz "Ueber den Verlauf der die Pupille verengenden Nervenfasern im Gehirn“" ${ }^{1}$ ).

\author{
Von
}

\title{
W. Bechterew.
}

Bezïglich meiner Abhandlung mit der Ueberschrift: Ueber den Verlauf der die Pupille verengenden Nervenfasern im Gehirn etc. $^{2}$ ) hat $V$. Hensen einige kurze Bemerkungen veröffentlicht, in denen er, ohne den wesentlichen Theil meiner Arbeit zu berühren, auf Unrichtigkeiten hinweist, welche ich betreffs meiner auf seine gemeinsam mit $\mathrm{Völkers}{ }^{3}$ ) ausgefülurte Arbeit bezüglichen Angaben begangen haben soll. Nur im Interesse der Wahrheit halte ich es für nöthig, hier einige Worte iiber diejenigen seiner Bemerkungen zu sagen, die eine Aufklärung nothwendig machen.

Allererst macht $\nabla$. He nsen mir den Vorwurf, dass ich seine gemeinsam mit Völkers ansgeführte Arbeit unrichtig citire, indem ich diesen Autoren die Verlegung des Centrums für willkürliche Bewegungen der Augäpfel an den Boden des dritten Ventrikels zuschreibe und nicht an den Boden des Aquaeductus Sylvii. An einem anderen Ort (Punkt 4) meint er, dass ich auch das Iriscentrum nach seiner und Völker's' Abhandlung irrthümlich an den Boden des dritten Ventrikels verlege, und nicht an die Hinterwand desselben. Der Autor der "Anmerkungen" fügt hier hinzu: „Die falsche Angabe des Autors (d. i. meine) wird von Bedeutung, weil er auf Grund derselben unseren Befund verwirft und dennoch unsere Ansicht, dass das erste Centrum der Oeulomotoriuskern sei, denn dieses liegt an der bezeichneten Stelle, völlig theilt."

1) Dies Arch. Bd. XXXI, S. 309.

2) Dies Arch. Bd. XXXI, S. 60.

3) Hensen u. Völkers, Gräfe's Arch. Bd. XXIV, 1874, S, 1. 
Betreffs dieser Bemerkungen habe ich Folgendes zu sagen:

Indem ich im Anfang meiner Abhandlung, in der Literaturübersicht (S. 62), auf die Untersuchungen von V. Hensen und Völkers hinweise, bezeichne ich die von ihnen angenommene Lokalisation des Iriscentrums im hinteren Abschnitt des Bodens des dritten Ventrikels als zwischen dem von diesen Autoren in derselben Gegend entdeckten Accomodationscentrum und dem Centrum für den M. rectus internus befindlich - also richtig ${ }^{1}$ ). Wenn ich dann im nachfolgenden Texte meiner Abhandlung, die nämlichen Unteršuchungen von Hensen und Völkers citirend, nur vom Boden des dritten Ventrikels spreche, so gebrauche ich, wie aus der allgemeinen Darstellung meiner Arbeit ersichtlich ist, diese Bezeichnung im weiten Sinne des Wortes, indem ich darunter den tiefen, von centraler grauer Substanz bekleideten Abschnitt des Ventrikels (also auch die Hinterwand desselben bis zur Mïndung des Aquaeductus Sylvii) verstehe.

Indem ich mich nun zu der von Hensen und Völkers in ibrer gemeinsamen Arbeit ubber den uns beschäftigenden Gegenstand auf Seite 16 gegebenen Beschreibung wende, finde ich Folgendes: „Erst wenn die Vierhügel abgetragen oder gespalten sind und wenn man den Boden des dritten Ventrikels bis $z u$ den corp. mamillaria hin untersucht, erbält man constante Resultate"; - und 4 Zeilen weiter: "In der Mittellinie und dicht neben derselben hat die Reizung der motorischen Oberfläche v on vorn uiber den corp. mamillaria beginnend zur Folge: Accomodation, Iriscontraction, Bewegung des Musc. rectus internus, dann superior, Levator palpebrae, Rectus inf., Obliquus inf., Trochlearis und weiter nach aussen Abducens". An anderer Stelle derselben Arbeit (S. 22) erwähnen die Autoren nur, dass der Anfang des Rectus inf. ganz von den Vierhïgeln bedeckt sei, der Anfang des Obliquus inf. unter dem hinteren Vierhügel liege; von den anderen Centren für die Augenbewegungen nimmt nach Bezeichnung der Autoren der Rectus int. den Grenztheil zwischen Aquaed. Sylvii und drittem Ventrikel ein, und hinter ihm liegen Rectus sup. und Levator palpebrac.

Da ich nicht Versuche mit Reizung oder Zerstörung des Bodens des Aquaed. Sylvii anstellte, konnte ich natürlicherweise

1) s. Hensen u. Völkers, l. c. p. 19. 
in meiner Abhandlung die Ansichten von Hensen und Völkers ïber die Localisation einiger Centren für Augenbewegungen in dieser Gegend weder theilen noch bestreiten 1). Meine Untersuchungen beziehen sich blos auf den tiefen von centralem Höhlengrau bekleideten Abschnitt des dritten Ventrikels, und ich bestreite nur diejenigen Angaben von Hensen und Völkers, welche auf diese Gegend Bezug haben, also die hierherverlegte Localisation des Iriscentrums und derjenigen Centren für Augenbewegungen, die von den genannten Autoren im Grenztheil zwischen Aq. Sylvii und drittem Ventrikel angenommen werden.

In meiner Arbeit führe ich $\mathfrak{u}$. A. die Ergebnisse von Zerstörungsversuchen der hinterseitlichen und hinteren Wand des Ventrikels an. In letzterem Fall wurde die Verletzung, wie in der Arbeit angegeben ist, an der Strecke vom Infundibulum bis zum Niveau des Aq. Sylvii angebracht, also an der Stelle, wohin Hensen und Völkers das Accomodations-, Iriscentrum und die Centren für einige Augenmuskeln verlegen (da auch der Grenztheil zwischen Aq. Sylvii und dem Ventrikel ergriffen war). Die von mir bei diesen Versuchen festgestellten Thatsachen (Fehlen eines völligen Verlustes der Lichtreaction der Pupillen, eigenthümliche mit der Zeit verschwindende Ablenkung der Augäpfel nach unten und innen wie auch begleitende Störungen seitens des Körpergleichgewichts) veranlassten mich eben das Vorhandensein eines Iriscentrums, wie auch irgend welcher anderen Centren für willkürlic̀he Augenbewegungen in der Gegend des dritten Ventrikels im Allgemeinen, also speciell auch in dessen hinterer Wand und dem Grenztheil, wie Hensen und Völkers annehmen, zu verwerfen ${ }^{2}$ ).

1) In meiner Arbeit (S. 74-75) mache ich nur die allgemeine Angabe, dass bisher kein Grund vorliegt die Centren für Bewegungen. der Augäpfel an einen anderen Ort $z u$ verlegen, als in die anatomisch gut bekannten Kerne der Augenbewegungsnerven. Hierbei gehörten Betrachtungen darüber, inwiefern die ausfïhrlichen Untersuchungen von Hensen und Völkers über Reizung des Bodens des Aq. Sylvii mit der anatomischen Lage der Kerne der Augenbewegungsnerven übereinstimmen, gar nicht zum Plan meiner Darstellung.

2) Die Iriscentren müssen, wie mir das Experiment zeigt (S. 71 meiner Abhandlung) in die tiefer liegenden Abschnitte der oberen Hirnschenkeletage, unter den vorderen Vierhügeln, verlegt werden, wo sie wahrscheinlich zu beiden Seiten der Mittellinie liegen. 
B. v. Anrep u. N. Cybulski: Ein Beitrag zur Physiologied. N. phrenici. 243

Die in meiner Abhandlung befindliche Aeusserung, dass Hensen und Völkers bei ibren Versuchen mit Reizung des Bodens des dritten Ventrikels durch die Bedinguugen ibrer Experimente selbst (Abtragung der gesammten Hemisphärenmasse mit den Ganglien) ausser Stand gesetzt waren, Zwangsbewegungen zu beobachten, nennt Hensen unrichtig; indessen behält für mich die Thatsache ihre Richtigkeit, dass Hensen und Völkers bei Reizung der hinteren Ventrikelwand, in welcher diese Autoren, wie aus Obigem ersichtlich, einige ihrer Centren lokalisiren, mit keiner Silbe allgemeiner Bewegungsstörungen Erwähnung thun, während dieselben bei anderen Versuchsbedingungen notbwendigerweise zum Vorschein gelangt wären.

(Aus d. physiol. Laboratorium des Prof. J. R. Tarchanoff in St.Petersburg.)

Ein Beitrag zur Physiologie des Nervi phrenici.

Von

B. v. Anrep und N. Cybulski.

Hierzu Tafel $\nabla$.

Mit Untersuchungen auf dem Gebiete der Innervation der Athmung beschäftigt fanden wir mitunter, dass die nn. phrenici, im Gegensatz zur allgemein verbreiteten Auffassung, gemischte Nerven sind. Bis jetzt wurden die nn. phrenici ausschliesslich als motorische Nerven des Zwerchfells betrachtet und das von Henle ${ }^{1}$ ) an der Hand anatomischer Thatsachen vermuthete Vorhạndensein sensibler Fasern in den Stämmen der nn. phrenici hat nicht nur eine Bestätigung in der experimentellen Physiologie gefunden, sondern die letzthin publicirten Beobachtungen von

1) Handbuch der Nervenlehre des Nenschen 1879, S. 521.

E. Pflüger, Arehiv f. Plyssiologie. Bd, XXXHI. 